\title{
Agricultura sustentável e agricultura racional: quais princípios e quais práticas para a sustentabilidade do desenvolvimento rural?*
}

\section{Sustainable agriculture and rational agriculture: principles and practices for sustainable rural development}

\author{
Samuel FÉRET** \\ Jean-Marc DOUGUET ${ }^{* * *}$
}

\section{RESUMO}

Este artigo tem por objetivo discutir dois modelos de agricultura na França: agricultura racional e agricultura sustentável, comumente confundidas pelo senso comum. Considerando esses dois modelos emergentes, com a crise do modelo produtivísta agrícola, o trabalho analisa seus princípios, as formas de organização social e produtiva e a relação com a natureza.

Palavras-chave: modelos de agricultura, França.

\begin{abstract}
The purpose of this article is to discuss two French agricultural models - rational agriculture and sustainable agriculture - which are often conflated in common sense. Considering both of these models as emergent, given the crisis of the productivist model, this paper analyzes their principles, forms of social and productive organization and their relationship to nature.
\end{abstract}

Key-words: agriculture models, France.

* Artigo publicado na revista Nature Sciences Sociétés, Paris, v. 9, n. 1, p. 58-64, 2001. Tradução de Alfio Bradenburg e Olivia Justen Brandenburg

* Titular de um DEA de sociologia, reponsável da missão agricultura sustentável no (FNCIVAM) Federação nacional de centros de iniciativas para desenvolver a agricultura e o meio rural. 14, Bd Volclair, 35203 Rennes cedex 2, France.<sferet @ wanadoo.fr>

*** Doutor em economia, pesquisador no C3ED (Centro de economia e de ética para o ambiente e desenvolvimento) Universidade de Versailles-Saint-Quentin-emYvelines. 47, Bd Vauban, 78047 Guyancourt, France. <jean-marc.douguet@c3ed.uvsq.fr> 
FÉRET, S.; DOUGUET, J-M. Agricultura sustentável e agricultura racional...

Entre uma agricultura dita convencional e uma agricultura biológica, a distancia acentuou-se largamente nestes últimos anos para o desenvolvimento de diferentes enfoques, visando a reconciliar agricultura e meio ambiente conforme uma agricultura com objetivos de um desenvolvimento sustentável. Todavia, isto que apenas parecia raro é uma visão de um conjunto de opiniões que prefigurariam a agricultura de amanhã. É forçoso constatar que, nessa matéria, as alternativas ou novos grupos não faltam, conforme se vê no quadro 1 , que os sete modelos agrícolas ilustram claramente. Desse emaranhado de tendências presentes, com a finalidade de esclarecimentos, limitaremos nossa análise a dois desses grupos. Trata-se da agricultura sustentável e da agricultura racional. Estes termos trazem equívocos como mostram certos slogans publicitários. "A agricultura racional base para uma agricultura sustentável"1 atrai particularmente a atenção sobre a natureza da sobreposição de dois termos que a priori têm a mesma significação para o senso comum. Este trabalho de explicitação é tão importante que esses termos estão no centro de numerosos debates sobre as opções possíveis de um desenvolvimento sustentável na agricultura na França. Nessa perspectiva, o recente relatório sobre a agricultura racional de $M$. Guy Paillotin ${ }^{2}$ é um exemplo. Certos pontos são assim entranhamente ocultados, notadamente no que se refere às concepções antinômicas do tipo de desenvolvimento e sua aplicação sobre as explorações agrícolas que permitem distinguir a agricultura racional da agricultura sustentável.

De um lado, para agricultura racional trata-se de justificar a manutenção de um modelo socio-técnico dominante racionalizando o produtivismo por uma integração e um mínimo de exigências ambientais excluindo todas as considerações de ordem social ou ética. De outro, para uma agricultura sustentável, de fazer mudar a agricultura no seu conjunto remetendo a política agrícola a um espaço de debate sobre a escolha da agricultura de amanhã com os atores da sociedade civil. A escolha de uma ou outra opção implica em estratégias de políticas públicas diferentes e remete sobretudo às seguintes questões de análise: qual é a característica sus- tentável destas opções? Qual é o horizonte temporal desta sustentabilidade? Quais são os benefícios esperados pela sociedade? Qual será o custo para a sociedade e para os contribuintes? Quais são os critérios objetivos e verificáveis que servirão de base à avaliação das práticas agrícolas? Quais concepções da sustentabilidade são priorizadas pelos atores socioeconômicos que promovem a agricultura racional e a agricultura sustentável? Isto prefigura a agricultura francesa de amanhã? Tais preocupações serão abordadas neste artigo.

\section{O enfoque técnico da agricultura racional}

A criação, em 1993, da rede Farre (Fórum para uma agricultura racional e respeitosa ao meio ambiente) por iniciativa das Organizações profissionais agrícolas (OPA), notadamente o FNSEA $^{3}$ e o IUPP $^{4}$ testemunham os primeiros sinais de uma pressão social em relação à agricultura para integrar a problemática ambiental (BONNY,1997; Dulcos, 1998). O risco de reprovação dos agricultores é acentuado no início dos anos 1990 quando o ministro do meio ambiente da época, Brice Lalonde, os qualificou de poluidores. O tema do meio ambiente se impôs logicamente como se os processos de intensificação da produção promovidos pela OPA desde três gerações não devessem ser colocados em questão. Então, diante da vontade comunicada da OPA sobre os recentes esforços dos agricultores de gerir o meio ambiente, quais são os conceitos e os métodos desenvolvidos no quadro da agricultura racional?

\section{Uma estratégia de comunicação dos agricultores}

As ações, levando em conta o meio ambiente, são fundadas sobre o voluntariado e o ajuste numa abordagem coletiva de proteção da água ( por exemplo, no quadro do plano de desenvolvimento sustentável) e um engajamento de um conjunto de prescribente. $O$ desenvolvimento da rede Farre tem igualmente permitido o re-

1 Extrato da regulamentação de agricultores do encontro de Farre, Agricultura racional, relatório dos sindicatos de agricultores.

2 Agricultura racional, relatório ao ministro da Agricultura, 2000.

3 Federação nacional dos sindicatos de agricultores.

4 União interprofissional para proteção de plantas.

5 SALMON, J. Le Paysan Morbihannais (1538, 1999, p. 3). 
encontro entre os agricultores e o público não agrícola a fim de trocar informações. Segundo seu vice-presidente, o percurso de Farre é um eixo para contribuir com o melhoramento da imagem dos agricultores. ${ }^{5}$ Essa iniciativa interprofissional francesa não é isolada na Europa. A Farre se aliou com as associações que tinham os mesmos objetivos nos outros países europeus, criando primeiramente o EIIF (European Initiative for Integrated Farming) e mais recentemente o Eisa (European Initiative for Sustainable Agriculture).

A agricultura racional pode assim se resumir como uma via que permite limitar os impactos da agricultura intensiva produtivista, mas que não questiona a maneira de cultivar, caso não seja por uma otimização de práticas atuais. Isto é um percurso que se realiza em nível de uma parcela agrícola ou de uma exploração e que somente faz apelo a um percurso coletivo, no contexto da circulação de informação e do processo de aprendizagem.

O objetivo primeiro permanece sempre o rendimento econômico no âmbito da exploração. Este critério está também no centro da agricultura sustentável, mas a procura de sua maximização passa por uma evolução na maneira de conduzir sua exploração.

Graças a uma operação de marketing, a comunicação sobre as práticas e os produtos oriundos da agricultura racional "já conduziu a validar as práticas ditas 'racionais' dentro de uma ótica de mercado, enquanto seus fundamentos se colocam somente em prática com referenciais técnico-econômicos muito variáveis e não validados" (DRON; PUJOL, 1999, p. 285).

\section{Os princípios de uma agricultura racional}

A agricultura racional se caracteriza por um forte desenvolvimento das técnicas e das ciências. Ela se define segundo Besnault (1998) como sistemática, isto é, numa concepção global no plano da exploração e de seu ambiente, uma agricultura competitiva e científica, que visa a uma produção de qualidade, que respeita e protege os meios nos quais ela se insere.

Mais precisamente, ela trata essencialmente de recomendações visando a evitar as práticas de superfertilização e a adotar métodos de fertilização racional, levando em conta a necessidade de limitar a fuga de ferti- lizantes em direção aos meios aquáticos: cálculo, espaçamento, época de aplicação das doses de fertilizantes, integração de dejetos animais numa racionalização da fertilização, gestão de intercultura (ou intervalo de cultura). Trata-se de limitar ao máximo o impacto da agricultura sobre o meio natural, desenvolvendo os produtos de qualidade. Praticamente isto se traduz por:

- apelo ao conhecimento científico e de especialistas para otimizar os aportes em nutrientes e mais genericamente as práticas culturais;

- o desenvolvimento de novos produtos menos nocivos para o meio ambiente (novos pesticidas, novos adubos, produtos geneticamente modificados etc.);

- o desenvolvimento de ações calcadas sobre o tipo "Ferti-Mieux" para se executar práticas culturais menos consumidoras em azoto. Por outro lado, as ações similares são conduzidos em torno de problemas de utilização dos produtos fitossanitários (Phyto-Mieux) e de irrigação (IrriMieux). No âmbito local, a operação implica na criação de um comitê de comando. No âmbito central, a operação é conduzida pela Anda (Associação Nacional do Desenvolvimento Agrícola) e é orientada por um comitê de comando e um comitê científico.

\section{Uma agricultura integrada ao complexo agro- industrial}

A lógica de intensificação produtivista não é, então, de forma nenhuma colocada em questão. Permanecemos no quadro de uma agricultura integrada num complexo agroindustrial, isto é, uma agriculturaem que subsiste uma forte dependência vis-à-vis das industrias agroalimentares, das cooperativas e dos negócios - para compras de produtos intermediários e venda de sua produção - das industrias de adubos e de produtos fitossanitários, de centrais de compras etc. Dito assim, são esses mesmos atores que como parceiros econômicos - como da CFCA por exemplo (Confederação francesa de cooperação agrícola) vulgarizam o conceito de agricultura racional em torno de seus adeptos (DRON; PUJOL, 1999, p. 546-549) 
O enfoque racional se constrói então, muito mais, como uma agricultura de referência segundo as regras de uma proteção jurídica de meio ambiente, do que como uma agricultura preocupada especificamente com o meio ambiente (DRON; PUJOL, 1999, p. 286). Assim, seguindo a diretriz européia sobre os nitratos(1991) e a regulamentação das instalações classificadas (1976), um código de boas práticas foi elaborado e proposto para uma adoção voluntária por um conjunto de agricultores. Sua elaboração foi demandada ao Corpen (Comitê de orientação para a redução da poluição das águas pelós nitratos e os fosfatos provenientes das atividades agrícolas). ${ }^{7}$ Ele trata notadamente da determinação da fertilização, de seu controle, das condições, dos períodos e das modalidades de distribuição dos fertilizantes, da estocagem dos dejetos animais, da ocupação dos solos.

É essencialmente através da rede Farre que o conceito de agricultura racional é vulgarizado entre os agricultores. Uma "legislação de encontro de fazendas" é proposta aos agricultores candidatos interessados em inscrever sua exploração no seio de uma rede nacional. A rede Farre coloca igualmente à disposição dos agricultores testes de autodiagnóstico ambiental a fim de avaliar a progressão dos sistemas de produção.

\section{O enfoque social da agricultura sustentável}

A história da agricultura sustentável tal como entendemos atualmente remonta, originalmente, aos primeiros grupos autônomos de desenvolvimento no início dos anos 1980. O relatório do presidente do Inra Jacques Poly: "Para uma agricultura econômica e autônoma", em 1978, já testemunhava a necessidade de reorientar a agricultura em direção a um desenvolvimento sustentável diante das crises que ela atravessava. Em 1982, o centro de estudos para o desenvolvimento de uma agricultura mais autônoma (Cedapa) é fundado na Bretanha sob a orientação de André Pochon. A partir de um enfoque econômico no sentido econômico do termo, o Cedapa demonstra rapidamente que numa escala de produção agrícola, conciliar economia e ecologia tornase possível, integrando além disso uma demanda social tanto em matéria de qualidade dos produtos como em termos de resultados sobre a qualidade da água. ${ }^{8}$

\section{A rede agricultura sustentável: um espaço de trocas e de aprendizagem}

A emergência de grupos e de associações de agricultores à margem de aparelhos de desenvolvimento institucionalizados responde a uma dupla afirmação: aquela do sujeito, ou seja, o indivíduo livre e senhor de sua história, e aquela do cidadão pertencente ao mundo (ARENDT, 1961, p. 41), portador de valores da vida em conjunto e de solidariedade. A constituição de grupos departamentais e intradepartamentais autônomos se explica pela seguinte maneira segundo o presidente da Rede agricultura sustentável (RAD):

A concepção descendente, qual seja, no alto há aquele que sabe e, em baixo, aquele que executa, o camponês, é um sistema que foi e que é sempre eficaz em se tratando de vulgarizar um modelo de produção. Quando não há um modelo a promover mas para imaginar outras formas de produção, nesse momento, a vantagem recai sobre o grupo de base com sua dinâmica: colocamos em comum a imaginação, as experiências (RÖLING et wadgemakers, 1998). Atualmente estes grupos de desenvolvimento constituem um espaço de liberdade para inventar novos sistemas de produção mais econômicas e mais sustentáveis" (GRIOT, 1994, p. 80).

Esta dialética da transmissão de saberes que é desenvolvida aqui remete explicitamente à escolha de um modelo horizontal de organização de projeto de tomada de decisão, que surgiu no Ceta ${ }^{9}$ nos anos 1950.

A agricultura sustentável convida a redefinir o lugar e a função da atividade agrícola na sociedade em relação ao aumento das incertezas através das expectativas sociais emergentes, mas também dos riscos e das crises que pressionam a agricultura. Esta constatação leva os agricultores e também os pesquisadores a se interrogar sobre a vulnerabilidade dos modelos de desenvolvimento quanto

\footnotetext{
O Corpen foi criado em 1984 por iniciativa dos Ministérios da Agricultura e Meio Ambiente.

Ver os anais do Colóquio do programa sistemas terra e água realizado em parceria com o Inra e o Conselho Geral de "Cotes d'Armor", abril de 1999.

Centro de estudos de técnicas agrícolas.
} 
a sua "sustentabilidade" no tempo (LANDAIS, 1966, 1998; COUGUET; SCHEMIRI, 2000), e a propor cenários de desenvolvimento sustentável que inteǵram as idéias de precaução e de responsabilidade de um novo paradigma.

\section{Práticas da agricultura sustentável em criações}

De início, a idéia deste percurso é que a eficácia econômica na agricultura não é uma questão de tamanho de produção ou de criação, mas de escolha de técnicas e de métodos de produção, de sua coerência geral de unidade de produção (RAD, 1998). Para o Cedapa, por exemplo Grupo Agricultura Sustentável Pioneiro - os pontos fortes giram em torno de seis elementos-chave no âmbito de uma criação $^{10}$ (POCHON, 1998, p.177) (quadro 1):
- trata-se de equilibrar criação e produções agrícolas. O solo produz os vegetais que os animais consomem; os dejetos destes últimos retornam ao solo propiciando assim a fertilidade de base e o húmus;

- O equilíbrio entre criação e culturas permite rotações variadas e uma boa gestão da exploração agrícola;

- Cultivar plantas adaptadas ao solo e ao clima;

- Criar os animais em abrigos com palha e não sobre o concreto;

- Os ruminantes (bovinos e ovinos) devem ser nutridos por mais tempo com ervas;

- Racionalizar os investimentos financeiros para facilitar a transmissão do instrumento de produção a longo prazo. Uma taxa de capitalização moderada é desejável e constitui um índice de durabilidade de produção.

\section{QUADRO 1 - ANDRÉ POCHON, O CAMPONÊS INOVADOR QUE CULTIVA OS CAMPOS DO POSSÍVEL}

Nós empregamos sem dúvida o qualificativo de "sustentável" quando qualquer coisa vem a faltar. A agricultura sustentável não é agricultura do vovô, ela não implica num retorno ao passado. Ao contrário é um projeto do futuro que se torna dia a dia mais pertinente, tendo em vista as crises recorrentes que atravessa a agricultura. A crise do ESB do fim dos anos 2000 e a interdição de farinhas animais na alimentação do gado, nos obriga a repensar um tipo de desenvolvimento agrícola que seja coerente com ela mesma. Para André Pochon, pioneiro da agricultura sustentável, é necessário procurar soluções simples e praticar técnicas apropriadas para criação: o milho não substitui a erva, porque as proteínas estão contidas nesta.

A história de André Pochon é aquela de uma geração de criadores que se lançaram no progresso técnico nos anos 1950, notadamente no seio do primeiro Ceta da Região da Bratanha, e o Corlay em 1954. Mas pouco convencido pelos meios de exploração do momento, ele elabora um sistema forrageiro baseado sobre a mistura ray grass-trèfle blanc. A revolução forrageira baseada na campina. O objetivo é de produzir ao menor custo, desen-volvendo todas as potencialidades da natureza e dela tirando melhor partido do solo, do clima das plantas, sem recusar o progresso técnico.

É assim que com poucos meios, mas muita observação de bom senso e de reflexão, ele e numerosos camponeses ganharam sua aposta: melhorar sua renda e sua qualidade de vida. Este pequeno homem ágil e teimoso foi quem criou o Cedapa em 1982, com a ajuda de seis companheiros criadores como ele. Por meio deste centro de estudos para um desenvolvimento agrícola, mais autônomo, os sete membros fundadores remaram contra a correnteza para praticar e promover uma outra agricultura, na época em que o modelo agrícola, Breton triunfava: para passar de uma lógica produtivista a uma lógica produtiva. Além das atividades do conselho e de orientação aos produtores adeptos, a associação dispensa uma quarentena de jomadas de formação, os pés na grama. Eles se dirigem aos criadores interessados em fazer evoluir seu sistema de produção em direçāo a práticas mais sustentáveis.

Assim sentido-se à vontade junto à Comissão européia para pleitear a causa da agricultura sustentável , como também para formar os agricultores de todos os países no cultivo de erva, mesmo até o Brasil, André Pochon sempre ilustra seu propósito da seguinte forma: “ a vaca é um animal maravilhoso. Ela está equipada de uma barra de corte à frente e de um distribuidor atrás". Subentende-se: porque insistir em fazer um trabalho de colheita de forragem e de incorporação como matéria orgânica em seu lugar?

10 Esses elementos constituem a arquitetura dos sistemas de normas da agricultura sustentável - e a do Cedapa em particular -, em vigor no departamento de "Cotes d'Armor" para a medida agroambiental "redução de entradas". 
FÉRET, S.; DOUGUET, J-M. Agricultura sustentável e agricultura racional...

Agricultor hoje aposentado, grande adversário do modelo agrícola produtivista e defensor de uma agricultura a uma escala humana, ligada ao solo e a um forte valor agregado, André Pochon milita incansavelmente nas associações para a reconquista da qualidade da água na Bretanha, instruindo as políticas agrícolas e os programas de controle de poluições agrícolas no interior das associações camponesas e dos cidadãos. Hoje, as trocas de experiências continuam nos grupos da Rede de Agricultura Sustentável, os programas de pesquisa se interessam pelos sistemas forrageiros à base de ervas, e o ensinamento agrícola integra os módulos de formação em agricultura sustentável. A agricultura sustentável é uma dinâmica global que prova que hoje é ainda possível manter uma agricultura a uma "escala humana" e de reconciliação econômica e ecológica.

Vinte anos após, o relatório de antigo presidente do Inra Jacques Poly "Para uma agricultura econômica e autônoma" permanece atual. Ele reforça o desempenho de certos camponeses que, como André Pochon colocaram suas idéias em prática, e talvez, erraram em ter razão muito cedo, se exonerando dos recursos ao milho, a soja importada e as farinhas de animais. As crises do modelo agrícola dominante serão sempre o único meio de dar lugar às alternativas? Como outros e com apoio das associações de consumidores e de proteção da natureza, André Pochon está convencido da urgência de reformar os mecanismos de suporte da agricultura, a fim de facilitar o desenvolvimento de uma agricultura sustentável "que deixe marca como uma mancha de óleo sobre o terreno".

Bibliografia de André Pochon:

La praire temporaire à base de trèfle blanc, éditions Cedapa, Plérin, 1981.

Du champ à la source, retrouver l'eau purê, éditions Cedapa, Plérin, 1991

Lês champs du possible, plaidoyer pour une agriculture durable, éditions Syros-La découverte, 1998.

Des soutiens à l'agriculture à l'agriculture soutenable, éditions Paysans, Rennes, 1998.

Este sistema visa uma busca de rendimentos, mas tendo a preservação do meio ambiente como critério para a tomada de decisão ele faça parte integrante do sistema de produção.

Nesse sentido, o RAD formou uma grade de avaliação da durabilidade composta de indicadores socioeconômicos e ambientais como guia de avaliação de sistemas de produção (BOUDIER, 1999, p. 2; VILAIN, 1999)

\section{A multidimensionalidade da agricultura sustentável}

A agricultura sustentável prioriza uma reflexão ampliada e global no que concerne à evolução da agricultura. Os agricultores da Rede de Agricultura Sustentável (RAD) definem a função e a característica de sua atividade, respeitando o equilíbrio das dimensões econômicas, sociais e ambientais da sustentabilidade. Trata-se de uma agricultura que é rentável e permite a transmissão da exploração agrícola graças a uma menor acumulação de capital dos sistemas mais econômicos e autônomos, uma melhor qualidade de vida e de trabalho, um levar em conta do equilíbrio natural nas práticas agrícolas, um respeito dos recursos naturais e uma melhor ocupação do espaço.

O RAD fixou-se nos seguintes objetivos:
- promover uma agricultura economicamente viável, socialmente eqüitativa e ecologicamente saudável.;

- apoiar os grupos nas suas ações e seus projetos, facilitando trocas de resultados e experiências entre agricultores;

- constituir um espaço cidadão de encontros entre camponeses, consumidores e ambientalistas (GRIOT, 1997, p. 92).

Pela recusa do sistema milho (que solicita fortemente o ambiente e as finanças européias) pelo questionamento das práticas intensivas, produtivistas e por sua participação nos movimentos de preservação de meio ambiente, esses agricultores se posicionam voluntariamente numa ótica de camponeses-cidadãos (nome de uma associação defendendo uma certa visão da política agrícola comum) e aderem igualmente à Rede "Cohérence" no Oeste da França (que agrupa associações de consumidores e de defesa da natureza e da saúde).

O desenvolvimento desse tipo de agricultura implica uma visão ampliada de evolução da exploração agrícola. Ela passa, além do mais, por uma menor concentração de criações, uma menor dependência de consumo intermediário (importados como a soja) e de subsídios europeus. O objetivo é então de reconciliar os desempenhos econômicos e os equilíbrios ecológicos, levando a exploração agrícola em sua globalidade em direção a práti- 
cas culturais - um sistema de forragem, a gestão de azoto e de pesticidas - que preservam a longo prazo o solo, a água, o ar, as paisagens e a qualidade dos produtos.

Em matéria de valorização, a produção - agricultura sustentável - não é nem certificada, nem etiquetada, isto é, nenhum selo oficial de qualidade a leva em conta. Nos encontramos por outro lado em alguns grupos de agricultores sustentáveis, iniciativas de comercialização de produtos que se desenvolvem; citemos o exemplo da Associação de pastagem de bovinos da Bretanha, e a Associação de produtores de porcos alternativos em
Mayene. O surgimento recente da agricultura sustentável é a ocasião de questionar sua inserção na produção mercantil e de conhecer os termos de sua filiação entre "lavoura e prato". A diversidade e autonomia dos grupos de produtores nos oferecem modos de valorização representativos. Segundo um dito popular que recomenda não colocar todos os ovos na mesma cesta, ${ }^{11}$ pode-se citar os seguintes exemplos de valorização: mercados, venda direta na fazenda, lojas de produtos artesanais na cidade, distribuição em grandes e médios supermercados.

\section{TABELA 1 - SUSTENTÁVEL, RACIONAL, INTEGRADA, CAMPONESA... O JOGO DOS SETE GRUPOS AGRÍCOLAS. GRADE DE LEITURA PARA COMPREENDER O EMARANHADO DE TENDÊNCIAS}

\begin{tabular}{|c|c|c|c|}
\hline Designação & Definição & Objetivos & Avaliaçâo \\
\hline $\begin{array}{l}\text { Agricultura } \\
\text { Biológica }\end{array}$ & $\begin{array}{l}\text { Conceito global que se apóia sobre a escolha de } \\
\text { valores como o respeito pela terra e pelos ciclos } \\
\text { biológicos, a saúde, o respcito pelo meio ambiente, o } \\
\text { bem-estar animal, a vida social etc. É um modo de } \\
\text { produção agricola fundamentado num conjunto de } \\
\text { técnicas complcxas que exclucm a utilização de } \\
\text { produtos sintetizados químicos. FNAB. }\end{array}$ & $\begin{array}{l}\text { - Respeito pelos } \\
\text { ecossistemas naturais; } \\
\text { - Respeito pela saúde } \\
\text { humana e animal; } \\
\text { - Busca de um } \\
\text { desenvolvimento econômico } \\
\text { coerente. }\end{array}$ & $\begin{array}{l}\text { - Sistemas de normas de } \\
\text { produção; } \\
\text { - Controles independentes; } \\
\text { - Certificação; } \\
\text { - Atribuição da marca AB. }\end{array}$ \\
\hline $\begin{array}{l}\text { Produçào } \\
\text { Familiar }\end{array}$ & $\begin{array}{l}\text { "Agricultura cuja especificidade reside no fato de } \\
\text { que as pessoas implicadas ocupam diversas funções: } \\
\text { a de produzir, transformar e vender scus produtos } \\
\text { junto aos consumidores. Os agricultores estão } \\
\text { implicados na evolução da sociedade: resposta à } \\
\text { cxpcctativa dos consumidores, criação de atividade e } \\
\text { de cmprego, revitalização dos territórios e } \\
\text { descnvolvimento de um cspaço rural vivo. Eles } \\
\text { participam, assim, da manutenção do clo entre } \\
\text { cidade e campo". FNAPF. }\end{array}$ & $\begin{array}{l}\text { - Criar valor agregado pela } \\
\text { transformação c pcla venda; } \\
\text { - Engajar-se num propósito } \\
\text { de melhoria de qualidade de } \\
\text { produto; } \\
\text { - Favorecer uma troca entre } \\
\text { produtor e consumidor; } \\
\text { - Participar de um } \\
\text { descnvolvimento } \\
\text { harmonioso do território. }\end{array}$ & $\begin{array}{l}\text { - Legislação nacional dos } \\
\text { fazendeiros; } \\
\text { - Sistema de normas por } \\
\text { produto e por terreno (a ser } \\
\text { concluído). }\end{array}$ \\
\hline $\begin{array}{l}\text { Agricultura } \\
\text { Camponesa }\end{array}$ & $\begin{array}{l}\text { A agricultura camponesa deve permitir a um } \\
\text { máximo de camponeses distribuídos sobre um } \\
\text { território, viver decentemente de seu oficio, } \\
\text { produzindo numa escala humana uma alimentaçào } \\
\text { saudável e de qualidade, sem comprometer os } \\
\text { recursos naturais do futuro. Ela deve participar com } \\
\text { os cidadãos na reconstrução de um meio rural vivo } \\
\text { num quadro de vida apreciado por todos. Fadear. }\end{array}$ & $\begin{array}{l}\text {-Respeito pelas sociedades } \\
\text { camponesas e pelo cmprego } \\
\text { agrícola c rural distribuído } \\
\text { sobre todo o território em } \\
\text { escala humana. }\end{array}$ & $\begin{array}{l}\text {-Legislação da agricultura } \\
\text { camponesa; } \\
\text {-Indicadores } \\
\text { socioeconômicos; } \\
\text {-Diagnósticos agro- } \\
\text { ambientais. }\end{array}$ \\
\hline $\begin{array}{l}\text { Agricultura } \\
\text { Sustentável }\end{array}$ & $\begin{array}{l}\text { "A agricultura sustentável convida a promover e a } \\
\text { praticar uma agricultura economicamente viável, } \\
\text { saudável para o ambiente c socialmente equitativa. } \\
\text { Esta agricultura é sustentável porque cla rcsponde às } \\
\text { necessidades de hoje (alimentos saudáveis, água de } \\
\text { qualidade, emprego c qualidade de vida) scm colocar } \\
\text { em questão os recursos naturais para as gerações } \\
\text { futuras." RAD. }\end{array}$ & $\begin{array}{l}\text {-Promover os sistemas de } \\
\text { produção autônoma e } \\
\text { econômicas; } \\
\text {-Tornar as explorações } \\
\text { viávcis, vitais e } \\
\text { transmissivcis; } \\
\text {-Construir espaços de trocas } \\
\text { entre camponeses e cidadãos. }\end{array}$ & $\begin{array}{l}\text {-Sistemas de normas por } \\
\text { produçào; } \\
\text {-Controles independentes } \\
\text { (em certos casos); } \\
\text {-Certificaçào (idem); } \\
\text {-Atribuição da marca da } \\
\text { agricultura sustentável } \\
\text { (idem). }\end{array}$ \\
\hline
\end{tabular}

11 Fórmula que se refere ao RAD, pois reconhece-se a diversidade dos modos e não a unidade de um modelo. 


\begin{tabular}{ll}
\hline Agricultura & "Agricultura competitiva que leva em conta, de \\
racional & maneira equilibrada, os objetivos econômicos dos \\
& produtores, as expectativas dos consumidores e o \\
& respeito pelo meio ambiente. A agricultura racional \\
& demonstra que é possivel conciliar: rentabilidade de \\
& exploração; preservação do meio natural; produções \\
& de qualidade, regulares e a preços acessíveis; \\
& contribuição da agricultura à economia nacional". \\
& Farre.
\end{tabular}

\begin{tabular}{ll}
\hline Produção & "Sistema agricola de produção de alimentos e de \\
integrada & outros produtos de alta qualidade que utiliza os \\
& recursos e mecanismos de regulação naturais para \\
& substituir os ingredientes prejudiciais ao meio \\
& ambiente e que assegura a longo prazo uma \\
& agricultura viável." OILB.
\end{tabular}

-Utilização racional dos produtos fitossanitários e dos adubos;

-Eixo de comunicação que visa a melhorar a imagem da identidade dos produtos agrícolas; -Tornar-se o futuro padrão da agricultura francesa.

\section{-Base de recomendações; -Guias profissionais técnicos; -Possibilidade de controle externo.}

\begin{tabular}{ll}
\hline Agricultura de & "Utilização das novas tecnologias que se \\
precisão & desenvolvem hoje no mundo agrícola para ajustar as \\
& práticas culturais o mais próximo da necessidade das \\
& plantas em função da heterogeneidade intraparcelar". \\
& Instituto técnico dos cereais e das forragens. (ITCF).
\end{tabular}
-Aumentar os benefícios e a competitividade dos
produtos;
- Adequar os instrumentos de
análise e de ajuda à decisão;
-Dominio da informaçào e
dos instrumentos de precisão
pelos agricultores;
-Levar em conta a proteção
do meio ambiente.

\begin{tabular}{|c|c|c|c|}
\hline Significado & Práticas & Atores & Enfogue \\
\hline $\begin{array}{l}\text { Agricultura } \\
\text { Biológica }\end{array}$ & $\begin{array}{l}\text {-Abrange todas as produçôes; } \\
\text {-Produtos químicos sintetizados interditados; } \\
\text {-Longa rotação de culturas; } \\
\text {-Gestão da matéria orgânica. }\end{array}$ & $\begin{array}{l}\text {-Federação nacional de agricultura biológica } \\
\text { (FNAB); } \\
\text {-Natureza e Progresso; } \\
\text {-Écocert; } \\
\text {-Cooperativas biológicas (Biocoop); } \\
\text {-Federação intemacional de organizações de } \\
\text { agricultura biológica (Ifoam). }\end{array}$ & $\begin{array}{l}\text {-Etico; } \\
\text {-Ambiental. }\end{array}$ \\
\hline
\end{tabular}

$\begin{array}{lll}\text { Produção } & \text {-Abrange todas as produções; } & \text {-Federação nacional de fazendeiros (FNAPT); } \\ \text { Familiar } & \text {-Matéria-prima oriundos exclusivamente da } & \text {-Federação nacional de centros de iniciativas } \\ & \text { fazenda; } & \text { para valorizar agricultura e o meio rural } \\ & \text {-Controle e responsabilidade do produto; } & \text { (FNCIVAM); } \\ & \text {-Transparência/consumidor; } & \text {-Confederação dos camponeses. }\end{array}$

-Conservação do espaço rural.

\begin{tabular}{|c|c|c|c|}
\hline $\begin{array}{l}\text { Agricultura } \\
\text { Camponesa }\end{array}$ & $\begin{array}{l}\text {-Abrange todas as produções; } \\
\text {-Autonomia em proteínas; } \\
\text {-Redução de entradas (inputs); } \\
\text {-Longa rotação de culturas; } \\
\text {-Gestão de pastagens; } \\
\text {-Produtos artesanais; } \\
\text {-Conservação do espaço rural. }\end{array}$ & $\begin{array}{l}\text {-Federação associativa para o } \\
\text { desenvolvimento de emprego agrícola e rural } \\
\text { (Fadear); } \\
\text {-Confederação dos camponeses; } \\
\text {-Coordenação camponesa européia; } \\
\text {-Via campesina (movimento camponês } \\
\text { internacional). }\end{array}$ & $\begin{array}{l}\text {-Sindical; } \\
\text {-Social. }\end{array}$ \\
\hline $\begin{array}{l}\text { Agricultura } \\
\text { Sustentável }\end{array}$ & $\begin{array}{l}\text {-Abrange as exploraçòes de policultura - } \\
\text { criação e criação; } \\
\text {-Redução de entradas (inputs); } \\
\text {-Longa rotação de culturas; } \\
\text {-Gestão de pastagens; } \\
\text {-Autonomia em proteinas; } \\
\text {-Conservação do espaço rural. }\end{array}$ & $\begin{array}{l}\text {-Rede de agricultura sustentável (RAD); } \\
\text {-Ensinamento agrícola; } \\
\text {-Instituições internacionais (OCDE FAO); } \\
\text {-Comissão européia. }\end{array}$ & $\begin{array}{l}\text {-Social; } \\
\text {-Institucional. }\end{array}$ \\
\hline $\begin{array}{l}\text { Agricultura } \\
\text { Racional }\end{array}$ & $\begin{array}{l}\text {-Abrange todos os setores de produção; } \\
\text {-Respeito à regulamentação; } \\
\text {-Normas de registros; } \\
\text {-Locais de estocagem fechados; } \\
\text {-Análise do solo; } \\
\text {-Regulagem do material. }\end{array}$ & $\begin{array}{l}\text {-Fórum para uma agricultura racional e } \\
\text { respeitosa ao ambiente (Farre); } \\
\text {-Indústrias fitossanitárias(UIPP); } \\
\text {-Sindicatos (FNSEA, CNJA); } \\
\text {-Câmaras de agricultura; } \\
\text {-Cooperação agrícola; } \\
\text {-Distribuição:Auchan, Casino. }\end{array}$ & $\begin{array}{l}\text {-Técnico; } \\
\text {-Agroalimentar. }\end{array}$ \\
\hline
\end{tabular}




\begin{tabular}{|c|c|c|c|}
\hline $\begin{array}{l}\text { Produção } \\
\text { integrada }\end{array}$ & $\begin{array}{l}\text {-Sistema mais utilizado na Europa do Norte } \\
\text { do que na França; } \\
\text {-Luta biológica relativa ao cultivo de } \\
\text { árvores, viticultura e culturas; } \\
\text {-Bem-estar animal; } \\
\text {-Longa rotação de culturas. }\end{array}$ & $\begin{array}{l}\text {-Organização internacional de luta biológica } \\
\text { (OILB); } \\
\text {-Produtores especializados em arboricultura, } \\
\text { viticultura, grandes culturas; } \\
\text {-Instituto técnico (ITCF); } \\
\text {-Política agrícola suiça. }\end{array}$ & $\begin{array}{l}\text {-Agronômico; } \\
\text {-Científico. }\end{array}$ \\
\hline $\begin{array}{l}\text { Agricultura de } \\
\text { precisão }\end{array}$ & $\begin{array}{l}\text {-Abrange as grandes culturas, o cultivo de } \\
\text { árvores, a viticultura; } \\
\text {-Novas tecnologias de informação; } \\
\text {-Instrumentos de medidas eletrônicas (GPS, } \\
\text { SIG, mapas e medidores de rendimento, } \\
\text { correção via satélite); } \\
\text {-Controle automático das máquinas e } \\
\text { equipamentos agrícolas. }\end{array}$ & $\begin{array}{l}\text {-Instituto técnico (ITCF); } \\
\text {-Pesquisa (Cemagref,Inra); } \\
\text {-Cooperativas de Abastecimento agrícola } \\
\text { (Uncaa); } \\
\text {-Agência nacional interprofissional de } \\
\text { aleaginosas (Onidol); } \\
\text {-Sociedade de informática e cletrônica. }\end{array}$ & $\begin{array}{l}\text {-Tecnológico; } \\
\text {-Informático. }\end{array}$ \\
\hline
\end{tabular}

NB: Foram selecionadas as características específicas à cada tendência, sem atingir a exaustão.

\section{Conclusão}

Definitivamente, o agricultor que se insere na ótica da agricultura racional tem escolha das práticas para atingir os objetivos socialmente definidos e aceitos (diretrizes nitratos, diretrizes sobre a qualidade da água etc). Tratase, assim, de uma evolução das práticas que podemos qualificar como técnicas, e isso no contexto de uma agricultura produtivista que satisfaz sobretudo os fornecedo- res dos agricultores. Para a agricultura sustentável, ao contrário, é a satisfação da renda dos agricultores que conta, e as maneiras de executá-la são delimitadas pelos sistemas de normas. Trata-se de uma evolução das práticas que precisa de uma mudança estrutural (crítica do produtivismo), já que atingir as normas não é o objetivo. Existem, sobretudo, considerações de ordem ética, social (empregos agrícolas e rurais), e evidentemente econômica que constroem a organização da agricultura sustentável.

\section{QUADRO 2 - O QUE É UMA AGRICULTURA CONVENCIONAL? SEGUNDO MARY V. GOLD, ALTERNATIVE FARMING SYSTEMS INFORMATION CENTER, USDA.}

Em oposição à agricultura sustentável, polariza-se facilmente a agricultura não sustentável, ou seja, agricultura dita convencional, clássica ou industrial. Entretanto, a identificação da filosofia e das características da agricultura convencional permanece muitas vezes ignorada, e, no entanto, ela permite melhor apreender as diferentes variações das agriculturas sustentáveis.

Características da agricultura convencional:

- tamanho relevante das explorações agrícolas;

- investimentos financeiros relevantes;

- alta produtividade;

- monocultura;

- especialização das produções;

- afluência massiva de entradas;

- dependência vis-à-vis das indústrias a montante;

- concentração das produções (sobretudo nas criações);

- difusão rápida da inovação tecnológica.

Filosofia da agricultura convencional:

- o progresso é adquirido pela evolução do tamanho da exploração agrícola;

- o progresso é medido pelo aumento do consumo material;

- a eficácia é medida pela relação com as desempenho dos concorrentes;

- A natureza é o suporte da competição entre os agricultores.

* Não se trata aqui de definir um tipo de exploração agrícola convencional, mas de enfocar as tendências gerais, as grandes atribuições e os critérios essenciais segundo os quais podese caracterizar a agricultura convencional e seus derivados produtivistas. 
Em conclusão, a decodificação desses dois enfoques, que são a agricultura racional e a agricultura sustentável, oferece uma base sobre a reflexão do desenvolvimento das agriculturas do futuro. A primeira que qualificamos como técnica e a segunda como social, para mostrar como, a partir de uma preocupação aparentemente comum de possibilitar um desenvolvimento sustentável da agricultura, os meios e os objetivos seguem caminhos opostos. Este trabalho precisaria inegavel-

\section{REFERÊNCIAS}

ARENDT, M. Condition de l'homme moderne. Paris: Calman Levy, 1961.

BESNAULT, C. L'Agriculture raisonnée, une iniciative interprofessionelle. Académie Agricole Française, v. 84, n. 2, p. 87-90, 1998.

BONNY, S. L'Agriculture raisonnée. Agriculture intégrée e Farre - Forum de l'agriculture raisonnée respectueuse de l'environnement. Natures Sciences Societés, n. 5, p. 64-67, 1997.

ROUDLER, P. À la rencontre de la agriculture durable. Mémoire d'ingénieur agronome. Rennes: Crsar, 1996. p. 16.

DOUGUET, J. M.; SCHERNBRI, P. Qualité de l'eau et agricultures durable. Rapport de recherché pour le ministère de l' Environnement et de l'Amenagement du territoire, contrat n. 97085, C3CD. Saint-Quintin: Université de Versailles, 2000. $69 \mathrm{p}$.

DUOOS, N. Les organizations profissionnelles et l'environnement. Écologie et politique, n. 23, p. 77-93, 1998.

GRIOT, J. Y. Communication aux premières rencontres de l'agriculture paysanne, 21-22, maio 1996 à Saint-Lo. L'agriculture paysanne,des pratiques aux enjeux de societé, dossier pour um débat. Paris :Fondation pour le progres de l'homme, 1994. p. 80.

Ensemble vers l'agriculture durable. Terre d'avenir. Nature et Culture. Fortent, 1997. 96 p.

LANDAIS, B. Élevage bovin et développement durable. Le courrier de l'environnement, n. 70, 1996. mente de um aprofundamento da análise da noção de sustentabilidade (quadro 2). De fato, além das dimensões econômicas, sociais, ambientais, intergeracionais que fundamentam a sustentabilidade de uma agricultura e das explorações agrícolas (LANDAIS,1998), nós não queremos ignorar o componente político, que é o mais determinante no final das contas, assim como as orientações a serem dadas ao desenvolvimento, e isso em função dos desafios sociais do momento.
_- Agriculture durable. Les fondement d'um nouveau contrat social? Lê courier de l'environement, n. 33, p. 5-22, 1998.

MINISTĖRE de l'aménagement du territoire de l'environnement, cellule strategie et prospective. In: ORON, D.; PUJOL, J. L. (Eds.). Agriculture, monde rural et environnement, qualité oblige. Paris: [ s. n.], 1999. 589 p.

PAILLOTIN, G. L'agriculure raisonée. Rapport au minister de l'Agriculture. Paris, 2000. 41 p.

POCHON, A. Les champs du possible, paldoyer pour une agriculture durable. Paris: Syros-La Découverte, 1998. 200 p.

POLY, J. Pour une agriculture econome et autonome. Paris: Inra, 1978.

PROGRAMME systemes tere et eau 1994-1999. Systeme d'elevage herbager et autonome en Bretagne. In: COLLOQUE INRA-CEDAPA, avril 1999, Bretagne. Actes... Bretagne, 1999. Conseil general 27.213 p.

RESEAU AGRICULTURE DURABLE. L'agriculture une chance pour l'emploi. Laval, 1998, 143 p.

TRANSKURAL INITIATIVES. Agriculture durable, les criteres... Paris, 1999. Dossiê coordonné par Boudier B. 8 p.

VILAIN, I. De l'exploitation agricole à l'agriculture durable. Dijon: Educagri, 1999.155 p.

VILAIN, I. Vers l'agriculture durable. Dijon: Educagri, 1999. $143 \mathrm{p}$. 